Revista Iberoamericana, Vol. LXIX, Núm. 202, Enero-Marzo 2003, 155-164

\title{
NIEBLAS EN LA RAZÓN. \\ CULTURAS, REGÍMENES Y PROCEDIMIENTOS POLÍTICOS, USOS DE LA MEMORIA Y POLÍTICAS NARRATIVAS EN LA ARGENTINA POSDICTATORIAL
}

\author{
POR \\ Jorge Bracamonte \\ University of Maryland at College Park \\ Universidad Nacional de Córdoba
}

A Magda y Julita

El fantasma de la memoria recorre la literatura y la historia argentina contemporánea. Y en cierta manera, este hilo de múltiples recuerdos enlaza lo puesto de relieve de modo central por la reflexión crítica al examinar el devenir cultural y literario durante el "Proceso de Reorganización Nacional” —las memorias de las violencias en los cuerpos-y lo que luego ha sucedido, es decir la restauración, las sucesivas transiciones y la formal consolidación democrática del país. Ahora bien, desde la perspectiva que permite configurar una heterogénea serie narrativa en sus relaciones con esa constante con variaciones en que ha devenido el espacio de la remembranza, puede resultar de interés examinar cómo se articulan esos diversos registros con la concreta trama históricopolítica. Por cierto, sin ignorar que en algunos aspectos la literatura siempre dialoga con marcos de larga duración histórica, lo que pretendo señalar es que el contexto de enunciación de cada texto — y sus decisivas marcas en el enunciado— de por sí describe cómo está actuando en su horizonte político, aquel que de acuerdo con Fredric Jameson define la hermenéutica más acabada de una producción simbólica. Quisiera, en la medida de lo posible, aportar elementos para comprender las condiciones que hacen a la persistencia de esas configuraciones problemáticas de la memoria histórico-cultural en el sistema literario, otorgando importancia a ciertos factores a decodificar en una hermenéutica política.

Durante los años del régimen burocrático-autoritario impuesto por el "Proceso de Reorganización Nacional” existieron diversos movimientos sociales de resistencia. Pero fue sobre todo con la acción que desde 1977 desarrollaron las Madres de Plaza de Mayo y otros organismos de derechos humanos que se evidenció el alcance del terrorismo de Estado - aquel que se sintetiza en las expresiones "delitos y crímenes aberrantes", "crímenes de lesa humanidad”-, implantado en la vida privada y social de la Argentina. Con esta mención subrayo cómo la restauración democrática de 1983 se asentó en un novedoso anclamiento en la jurídica internacional de derechos humanos. Tal como lo marca Hernán Vidal (1989): la relevancia que cobraron éstos en la cultura y vida social de la América Latina contemporánea se entiende fundamentalmente como réplica a la 
implementación sistemática del terror fascista que asoló el continente en las últimas décadas. Pero a la vez, por esta misma razón, ese profundo impulso humano, cultural y social reforzó la legitimidad de algunas nuevas democracias continentales. Esto -y hablando aquí puntualmente del caso argentino — no fue visualizado desde un principio por toda la sociedad. Mas, sin duda, actuó incorporando fundamentales elementos a la democracia que en ese momento se refundaba otorgándole un correlato, a nivel de legitimidades políticas y jurídicas, a cuestiones centrales en el plano simbólico-cultural como es todo aquello referido a la memoria social. Para delinearlo más claramente: la Constitución Nacional de por sí se enmarca en jurídicas internacionales como la Declaración Universal de los Derechos Humanos de las Naciones Unidas (1948), entre otras. Pero además, la actualización de esa Constitución, en una inédita revalorización de la democracia que acontece a partir del bienio 1982-83, alimenta de modo central su legitimidad en el reclamo por la reparación de los derechos humanos básicos violados por el autoritarismo (y la economía neoliberal que fue su correlato), y que recobran un hondo valor por lo acontecido en el dominio histórico-político. Esto hace al decisivo alcance institucional y simbólico del proceso que desemboca en la elaboración del Nunca Más. Informe de la Comisión Nacional sobre la Desaparición de Personas (1984), encomendado por el presidente Raúl Alfonsín, que culmina luego en el Juicio a los ex comandantes de las Juntas Militares (1985). Si las sentencias de la Cámara Federal a los jefes militares del "Proceso" por sus responsabilidades en la implementación del terrorismo de Estado — tras un juicio impecable ante la comunidad nacional e internacional- fueron, aun con sus límites, ejemplares en función de una sanción a la memoria de lo hecho por la dictadura y como legado al futuro democrático, esto mismo consolidó desde la macropolítica lo que venía produciéndose en la micropolítica.

Como ha señalado la reflexión política, entre el retiro de las autoridades militares y la asunción del gobierno democrático se produce una primera transición, que implica un cambio formal de régimen. Y entre este cambio y la deseada consolidación del régimen democrático se produce una segunda transición. Ahora bien, para el desarrollo de este proceso a la sociedad argentina no le bastaba con un cambio en términos macropolíticos; debían producirse, tal como indicara Guillermo O’Donnell ya en 1983, profundos cambios a nivel micropolítico, desde la trama cotidiana de la vida social y cultural (133-46). Sin esto, lo ocurrido en el otro nivel — el de las grandes decisiones del Estado y la políticaiba a tener un efímero alcance. Lo cual, con idas y venidas, se desarrolló; en el cuerpo social se fueron contrarrestando - no definitivamente, duele admitirlo- los ideologemas de “orden autoritario”, “violencia estratificada” y “microdespotismos” que habían definido en el sustrato la cultura política de la dictadura. La revalorización de la justicia, las aspiraciones a la equidad plural y la necesidad del diálogo y consenso para reconformar un espacio público, eran nuevos registros culturales que daban otra legitimidad a las conductas de los actores sociales y políticos; estaba pendiente qué tipo de democracia se quería para la nueva sociedad. Decisivamente, el Juicio a las Juntas Militares realimentó lo que se producía en dicho momento desde lo microcapilar de la sociedad.

Dinámica histórica — la anterior — que puede dar un idea de la crisis en la transición que se produce luego, a partir de 1987, con las sucesivas concesiones del Estado ante los 
movimientos de insubordinación y rebelión de la corporación militar ante la autoridad constitucional. Porque la secuencia que se inicia durante el alfonsinismo con el dictado de las leyes de Punto Final (1986), Obediencia Debida (1987), hasta llegar a los sucesivos indultos presidenciales decretados por el presidente Carlos Menem en 1989 y 1990, lejos de "consolidar" la "democracia” mediante la "reconciliación nacional” — como se decía desde el poder- implicó un trágico retroceso, ya que al deshacer institucionalmente lo iniciado con el Juicio a las Juntas el poder político negaba lo que había basamentado la refundación democrática. Esto ubica una coyuntura muy precisa que debilita el régimen democrático, lo que se agudiza a medida que transcurre la década de 1990. Si las políticas de la memoria habían refundado la democracia para que deviniera régimen representativo y participativo y no sólo sucesión de elecciones y consultas formales, la regresión desarrollada entre 1987 y 1990 lleva a que el régimen democrático se resienta hasta culminar durante los dos gobiernos de Carlos Menem en una democracia tendiente a lo "formal", a ser "suma de procedimientos", supeditados en gran medida a la arbitrariedad del poder político y las clases dominantes (Castoriadis 267-91). Se produjo así una paradójica postransición, consolidación formal del régimen democrático — traducida en una marcada desregulación legal e institucional del ejercicio del poder del Estadomixturada con una actualizada aplicación de políticas económicas neoliberales que sobre la base de las “políticas de olvido” desarticularon el régimen de acumulación social y los impulsos hacia la igualdad del conjunto de la sociedad (fue un momento donde se volvió a acentuar el formidable deterioro del aparato productivo nacional y el endeudamiento externo heredado de la dictadura). Marco que, en definitiva, resultó propicio para un vigoroso renacimiento de tendencias autoritarias —algo que siempre había estado latente- y de un pragmatismo político sostenido en gran medida en el clientelismo - fomento de la corrupción-, lo que por otra parte se tradujo en una manifestación restringida de los intereses del conjunto de la ciudadanía.

\section{Políticas NARRATIVAS EN UN MARCO PARADÓJICO}

Es por eso que en la vida social, en el trayecto que con diversos matices va del primer lustro de los ochenta a los noventa, se pasa de las utopías al desencanto, de la euforia y la esperanza a la disforia y la acentuación del escepticismo. Así, en este sentido, hubo una permanente búsqueda — compleja, plagada de inusitadas contradicciones en la dialéctica entre pasado, presente y futuro- - del campo intelectual argentino, que asimismo fue desde una discusión en torno a la nueva política democrática a construir (primer lustro de los ochenta) a una evaluación de la crisis de la política (segundo lustro de dicha década y principios de los noventa), hasta llegar a una incredulidad en torno a las posibilidades reales de una política participativa y representativa (durante los noventa).

Si antes ensayé una posible narración de un movimiento histórico paradójico, es porque me interesa sobreimprimir al mismo las maneras en que lo interrogan diversas producciones literarias. Comencemos por La revolución es un sueño eterno (1987), de Andrés Rivera (1928). En esta novela el anclaje es multirreferencial. Si bien centrada en lo que escribe Juan José Castelli mientras vive dos procesos simultáneos —el del juicio 
de sus opositores saavedristas en la Junta de Gobierno de la Revolución de Mayo y el de su cáncer de lengua-, la enunciación contacta dicho tiempo histórico con el de otros destinos de revolucionarios “jacobinos” de esa y otras épocas — “Apéndice” (16570)—, y el tiempo coetáneo de los editores, narradores — junto a Castelli y su hijo—- del texto. Así se rompe, de modo radicalizado, la ilusión mimética en un mundo que, no obstante, se reconoce por referencias a un pasado histórico existente. ${ }^{1}$ Esto hace a algo crucial del relato: no importa sólo lo que (re)presenta, sino sobre todo el proceso y las maneras de escribirlo. Lo cual adquiere verdadera relevancia: La revolución es un sueño eterno es un texto donde la retórica escrita, la letra de un alegato, adquiere el verdadero protagonismo, otorgándole por este movimiento real actividad a quienes escriben, leen y descifran la historia, usándola desde una posición. Carmen Perilli ha subrayado varias cuestiones: la tensión escritura/historia como constitutiva de la novela; el conflicto entre revolución y poder que define su sentido; las legitimidades literarias y políticas - liberales, marxistas, peronistas y nacionalistas - que reescribe y respecto a las cuales se posiciona el texto. Pero — enfatiza la crítica — todo esto está asentado en una intensa reflexividad, no sólo sobre el proceso de escribir sino también sobre los poderes de la escritura (Perilli 135-47).

A lo anterior, agrego lo siguiente que, a mi criterio, instala en el presente un texto que quizá más que ser una narración rigurosa en la presentación de los materiales históricos es fundamentalmente una reflexión sobre la dinámica entre poder, historia y memoria. Varios juicios configuran las escrituras - los “cuadernos”— en la narración: el de Castelli ante sí mismo, ante sus allegados, ante el fracaso de la Revolución, ante sus jueces “enemigos” y ante una "verdad” histórica. Y en la novela asistimos a un teatro, el "Teatro del Juicio”; pero quiénes y cómo juzgan varían según la ubicación en el enunciado textual. Puede conjeturarse que al ver Rivera en Castelli el antecedente de tantos revolucionarios que habían sufrido la derrota (quien, además, habiendo sido el “Orador de la Revolución” terminó padeciendo cáncer de lengua, lo que delinea aún más fuertemente este texto como paradoja), se preocupó sobre todo por tender un puente crítico de lenguaje entre aquel momento histórico y el presente. La referencia en el "Apéndice” a un revolucionario bolchevique - preso en los campos de concentración de José Stalin-y a León Trotzky, y la definición polémica que la enunciación textual tiene respecto a los legados marxistas —alguno de los cuales reivindica el escritor — y nacionalistas —en particular Juan Perón, cuya visión cuestiona desde la tradición utópica-, posicionan la política de la lengua desde la que se enuncia en el presente. En éste asume su confrontación con la ley impuesta por un poder que no es “neutral”, pero también la polémica con sus propios pares políticos y los "vencedores" de la historia. No son ajenas a este contexto, sino todo lo contrario, las búsquedas y disputas de verdades jurídicas que definen los primeros años democráticos (la idea de la novela surge en 1985, se publica en 1987). Pero además está otro elemento: el de la reivindicación de la "utopía” desde una tradición marxista, cuando al mismo tiempo en el campo intelectual dicha tradición se ve ramificada entre corrientes neomarxistas

\footnotetext{
${ }^{1}$ La presente lectura dialoga con los enfoques de la Nueva Novela Histórica. Al respecto, ver María Cristina Pons (42-109, 254-69). Sobre el perfil de los jacobinos argentinos que traza la novela, confrontar con el examen que sobre la etapa realiza Nicolás Shumway.
} 
y otras que, con diversos matices, reivindican posiciones más duras de juicio respecto a la nueva democracia "burguesa” refundada. Lo que se enlaza con otro dato: si el gobierno de Alfonsín —y con él los partidos populistas mayoritarios del país— había organizado su revisión del terror en Argentina en base a la “Teoría de los dos demonios” (gravitante, junto a la reivindicación del Estado de Derecho, en la "Introducción” del Nunca Más), la novela de Rivera replica a dicha posición del Estado redemocratizador con la sugerida afirmación (auto)crítica de que la derrota no la había sufrido un "Demonio de Izquierda" frente a la dictadura sino toda una generación revolucionaria en manos del Estado genocida. Lo que se relaciona con otras evaluaciones simbólicas de esta etapa —y los años siguientes- que se vuelven impugnadoras, como interrogando en el sustrato las tensiones autoritarismo/democracia, guerra/convivencia, que atraviesan los eufóricos años posteriores a 1983. Porque en definitiva, la memoria-testamento dejada por Castelli — y que el lector puede reorganizar discutiendo barthesianamente la autoridad del autor- no solamente expone un juicio ante y contra el poder, sino que además cuestiona la dinámica irracional que puede llevar a que ese poder se vuelva de este modo arbitrario y antiutópico respecto a la sociedad.

Antiutopía que se agudiza, anclada decididamente en el presente, en El Dock (1993), de Matilde Sánchez (1955), novela diseñada entre la autobiografía y la biografía que incorpora, a partir del trágico asalto al Regimiento de "La Tablada" (transformado en la ficción en el “Dock”) por parte de una agrupación guerrillera (1989), el clima de violencia y militarización en la vida social que subyace en el país democrático. La narradora, quien termina adoptando al hijo huérfano de una lejana amiga guerrillera muerta en el asalto, reconstruye en su relato la memoria de las otras memorias implicadas en el imprevisto hecho, reconstituyendo así la conformación de una serie de identidades que se encuentran girando de pronto en torno a ella y a Poli, la otra mujer-madre-guerrillera-víctima de la violencia estatal-militar. Si la dictadura había irrigado con el terror cada familia del país, aquí es un hijo - Leo- quien termina preguntando(se) por su madre (a la inversa de las Madres de Plaza de Mayo) en el arduo proceso que deviene la narración. Además, como ya está presente en el relato de Rivera, no sólo surge el problema de las identidades sino que sobre todo preguntar y preguntarse por las mismas es reconocerle una historia personal, social, política y cultural que muestra diversos momentos y transformaciones, algunas de las cuales no dejan de ser polémicas y difíciles de comprender para la voz que narra. Decididamente El Dock se inscribe en una sociedad de latente militarismo, pero que vive esto como algo a la vez "real” y “construido" por los medios de comunicación (la dialéctica entre materialidad, corporeidad y simulacro es clave para el relato): en la conjunción de ambos órdenes se transforman las experiencias de la nueva Poli, Leo y Kim. Si en Los planetas (1998) de Sergio Chefjec (1956) es el cuerpo de un hombre desaparecido el que se recupera en la ley del relato, aquí es el de una mujer desaparecida (aunque en un presente posdictatorial: ésta es la paradoja). La cuestión del género confluye con los otros, a veces contradictorios, componentes de la identidad (una noción básicamente jurídica). La memoria es el punto de partida de la novela y, tras el proceso de la narración, es una nueva llegada, más integral.

Resulta notable cómo El Dock retoma y transforma en sus máximas posibilidades simbólicas una referencia a la “actualidad” política y desde ahí construye una huida micro- 
utópica, familiar, de la persecusión paranoica que se instala en la sociedad condicionada por la influencia de la corporación militar (segundo lustro de los ochenta y noventa). ${ }^{2}$ Ya la familia, en cambio, se ha desintegrado en La ciudad ausente (1992), de Ricardo Piglia (1940); Junior está lejos de su hija, ha perdido a su mujer. Está solo y lo único que tiene es su propia historia — núcleo de su identidad—y su azarosa vinculación con la máquina Elena, inventada alguna vez por Macedonio Fernández para preservar la memoria de su mujer; máquina que aún encerrada en el museo por el Estado paranoico no deja de producir variantes de los relatos que proliferan en la sociedad. Si la Realpolitik ha devenido el principio de realidad impuesto por el Estado que condiciona la sociedad antiutópica que en código de ciencia ficción presenta la novela, el cuestionamiento al ejercicio de la fuerza, al poder de dicho Estado, parte de lo conspirativo que se alimenta de lo capilar, molecular de la sociedad. ${ }^{3}$ La literatura entonces es máquina que toma, transforma y hace dialogar la discursividad social, desestructurando el control estatal. Piglia ha marcado el origen de la novela no sólo en la pérdida de una mujer, sino también en la memoria de otras (Piglia, Formas 43-6). Estas - literarias, históricas - en la ficción, como voces que se vuelven contra el poder, adquieren una función decisiva y son las que realimentan la memoria utópica. Y se articulan con el otro elemento, la máquina/archivo — código asimismo fuerte en la teoría crítica y literaria-, como artefacto simbólico y material de resistencia ante el poder. Frente a la impunidad del accionar de éste, La ciudad ausente reactiva los legados políticos utópicos y los legados literarios: en la conjunción de ambas series de legitimidades se produce la oposición cuestionadora al presente político antiutópico. También aquí las memorias e identidades recuperadas hablan de lo residual negado en el presente de los noventa en Argentina: memorias de la "resistencia peronista" — en una coyuntura donde esos legados están fragmentados tras la coalición del menemismo con el neoliberalismo y los grupos económicos más poderosos, que busca condicionar y reificar la sociedad desde el poder estatal— o del Ejército Revolucionario del Pueblo, se enlazan con la "resistencia” irlandesa, en un aleph joyceano. Y cuando Junior escucha el último relato de la máquina —el primero leído en la novela—, se incorpora a la estructura ficcional "la voz de un testigo que contaba lo que había visto (...) los signos del horror marcados en la tierra” (31): se actualiza en esta narración de 1992 la memoria de los desaparecidos, con la alusión a uno de los campos de concentración testimoniados en el Nunca más (200). En este sentido La ciudad ausente es una réplica de fuerte condensación simbólica a la secuencia de impunidad abierta en 1986 y culminada en 1990 con los indultos presidenciales. Y expone en esta dirección un nuevo diseño posible de la novela política en Argentina. ${ }^{4}$

\footnotetext{
${ }^{2}$ Para un análisis atento a la tensión memoria/simulacro en El Dock, ver Morello-Frosch.

${ }^{3}$ Otro proyecto literario que trabaja la codificación de la política en la ciencia ficción es el de Marcelo Cohen. Respecto a la memoria como resistencia al autoritarismo de las corporaciones locales del capitalismo neoliberal ver, entre otros, El testamento de O'Jaral (1995) y Hombres amables (1998). ${ }^{4}$ Si bien Respiración artificial se termina de conformar en el contexto dictatorial de 1980, ya estaba en proceso de escritura en 1972. A la vez La ciudad ausente aparece en 1992, aunque tuvo una primera versión no publicada en 1985 y puede considerarse, como ha señalado el propio escritor, que “Notas sobre Macedonio en un diario", incluido en Prisión perpetua (1988), es otra versión de la novela. Posiblemente las fechas señaladas respecto a las novelas sugieren algo: que los contextos antiutópicos, disfóricos, establecen un máximo de tensión posible para el logro final de la
} 
Por la incidencia de lo planteado por Piglia en el campo literario, conjugo lo anterior con algunos núcleos conceptuales señalados por el escritor en Crítica y ficción (sucesivas ediciones en 1986, 1990 y 2000). Aquí, además de trazar reflexiones teóricas sobre las articulaciones literatura-política-ideología, dispone una mirada inventiva sobre cómo leer la política en la literatura y qué implica desarrollar políticas literarias en tensión con los discursos sociales. Pero más allá de los legados literarios que configura Piglia en este texto, marco otra cuestión: cómo el escritor-crítico pone en tensión literatura (o novela o ficción) con política (Estado). En esta dirección si, como dice el mismo Piglia, la crítica de un escritor es un espejo para leer su propia obra, Crítica y ficción cifra la estructura narrativa de La ciudad ausente por dicha oposición. Y entre ambos está lo social, esa "trama de relatos" que también alimenta la literatura y que tiene una base material (Crítica, 9-20, 43-52). Esto, que en La ciudad ausente da en cierta medida los relatos que reelabora la máquina, se incribiría — no exclusivamente- en los contextos discursivos de lo micropolítico de lo cual hablé en páginas anteriores. ${ }^{5}$ Por otra parte, en Crítica y Ficción - como en toda la producción pigliana — cobra relevancia la reflexión no solamente sobre el género policial — el género de la modernidad, constituido entre la ley y la verdad—, sino también la indagación sobre la circulación de lo policial en el Estado y la sociedad. Pensar sobre la criminalidad del Estado no es sólo ya una imagen del régimen dictatorial: recobra otra vigencia desde la política narrativa pigliana a la luz del debilitamiento del régimen democrático.

La pesquisa (1994), de Juan José Saer (1937), recorre una vez más la cuestión de la memoria en la producción saeriana, si bien aquí este núcleo entra en oposición directa con lo criminal que circula por la vida social y política. En un plano, está la historia de los crímenes de París que cuenta Pichón Garay a Tomatis y Soldi, quienes aportan sus variantes. El asesino, al ser jefe de la institución encargada de vigilar el cumplimiento de la ley en la sociedad, indica con sus crímenes el grado de impunidad y corrupción que puede estructurar dichas instituciones. En este sentido se tensionan la historia policial incluida con el relato incluyente, aquel que habla no sólo de las memorias e identidades de una sociedad localizada — la de Tomatis, Pichón Garay, Soldi y toda la comunidad antropológica construida por Saer en la continuidad de sus textos - sino también de las memorias e identidades de los desaparecidos de esa comunidad, familiares, en este caso, de los actores ficcionales. Al insistir La pesquisa en la pregunta sobre el destino de los

articulación entre códigos políticos, ideológicos y literarios en la escritura pigliana. Respecto al anclaje histórico de La ciudad ausente, a lo dicho agrego detalles como la palabra "peronios" y el neoliberalismo que aparecen —en tanto opuestos de la sociedad presentada en la ficciónarticulados respectivamente con el Estado despótico y la sociedad fragmentada que figurativiza el texto. Si en la primera novela de Piglia, Marcelo Maggi también era emblema de la antigua crisis que arrastraba la identidad del partido radical, en La ciudad ausente Emilio Renzi en su discurso vuelve todavía más evidente la crisis coetánea de la identidad peronista. Por otra parte, en la narrativa de Piglia es relevante la problematización de la ley, tal como ha subrayado Adriana Rodríguez Pérsico (22-3).

${ }^{5}$ Los tiempos-espacios de la micropolítica son importantes en la conformación del artefacto literario; éste les puede otorgar el mayor alcance imaginario y simbólico en dicha interdiscursividad que a su vez localiza el artefacto. 
desaparecidos — con la incertidumbre sobre sus memorias desde el presente narrativoreformula una línea literaria que, iniciada durante el "Proceso", atraviesa toda la década de 1980 hasta reconfigurarse en los noventa en consonancia con nuevas instancias de la memoria social en el marco de las “políticas de olvido” desarrolladas desde el Estado. Ya sea desde el material histórico (Rivera), la actualidad vuelta narración intimista (Sánchez), la interrogación trágica desde la articulación entre los legados literarios y políticos como narrador y crítico (Piglia) o el género policial figurando lo social (Saer), la problemática de las memorias e identidades desaparecidas o violentadas en la historia contemporánea del país es abordada una y otra vez y adquieren diversas resoluciones simbólicas en los sucesivos lustros.

Para concluir, destaco las exploraciones que proponen dos novelas del segundo lustro de los noventa: Villa (1996) de Luis Gusmán (1944) y Vivir afuera (1998), de Rodolfo Fogwill (1941). Ambas, por la materia narrativa que manifiestan, ubican uno y otro posible borde de los marcos institucionales desgarrados que hacen a la producción, interrogación y usos de la memoria en la trama de culturas políticas en conflicto de la Argentina. Villa, al indagar — desde una memoria que nunca quiso "saber" demasiado ni cuestionar su entorno de microautoritarismos - el lapso histórico que va desde los días de la muerte de Perón (1974) hasta el golpe de Estado de 1976, reubica una coyuntura de profunda crisis institucional del país, de asentamiento burocrático del autoritarismo, de reificación de los ciudadanos y de desregulación estatal de la violencia política en lo público y privado con la consiguiente eliminación de cuerpos e identidades cuando aquello atrozmente deviene. Al principio de la narración está terminando la Argentina de un tipo de participación social y civil; al final, sólo prevalece el país ocupado por la represión institucionalizada. Enunciada en 1996, la novela, con su figuración del micro y macroautoritarismo y la fragmentación irracional del Estado-Nación, interroga un contexto donde la crisis de institucionalidad democrática manifiesta el retorno posible de la violencia en la interacción de los actores sociales. En cambio Vivir afuera, que manifiesta un vasto plurilingüismo de los noventa, localiza en su enunciado las condiciones trastocadas de enunciación institucional de la memoria social en la Argentina coetánea. La múltiple serie de memorias - las de la guerra de las Malvinas y el presente de los ex combatientes, las de los enfermos terminales en una sociedad pauperizada, las de quienes han crecido en una educación jerarquizada y prejuiciosa, las de los miembros de la comunidad judía en el contexto de los atentados contra sus instituciones, las de los marginales que viven en el clientelismo corrupto de políticos y ricos - trata de llenar ese "vacío de memoria” que se le ha formado a Wolff, el escritor, que es una de las seis voces que organiza la polifonía novelesca. ${ }^{6}$

${ }^{6}$ La problematización mnemotécnica es una constante desde los primeros relatos de Fogwill. “Memoria de paso" (de Mis muertos punk [1980]) y "Sobre el arte de la novela” (de Pájaros de la cabeza [1985]), entre otros, son de los relatos que más tensan el vínculo memoria/arte narrativo. Por otra parte, Vivir afuera remite de modo directo en el sistema expresivo del escritor a Los pichycyegos (1982), un texto capital para revisar los traumáticos recuerdos de y sobre las Malvinas en la cultura argentina. En el caso de Fogwill, como en el de los otros escritores incluidos en este recorrido, lo que aquí analizo puede ponerse en relación con el conjunto de su producción y con otras poéticas narrativas del período. 
Villa y Vivir afuera culminan en lo formal una serie que, enlazando la política en la literatura y las políticas literarias con el uso de las memorias y las disputas por la verdad en la vida social, recurre en explorar las posibilidades de las modalidades discursivas jurídicas en su interdiscursividad con los géneros literarios: el testimonio, el testamento, la declaración, lo policial, la pesquisa, el informe, los archivos, el sumario, los discursos del poder estatal, los múltiples discursos sociales, el alegato y la retórica escrita, los indicios y pruebas de identidad, lo biográfico, lo autobiográfico y las "memorias" devienen maneras de reconfigurar una diversidad diferenciada de memorias e identidades privadas y públicas, individuales y colectivas, a recuperar, a develar, a re(in)stituir. Revisada desde este lugar, no sólo la historia política (la de la Sociedad y el Estado, la micro y la macro), sino también la literaria adquiere otra dimensión. Porque no es casual que esta interacción dialógica motive simultáneamente otro tipo de recepción, transformación y transgresión de los legados literarios que cada poética actualiza en el sistema. Considero que ello se vincula no solamente con un notable cambio en los enlaces entre las discursividades de la política y la literatura en la etapa postdictatorial, sino que eso mismo - las formas de la ley, la construcción y valoración de verdades jurídicas en la racionalidad democrática, las disputas por restituir identidades- actuó decisivamente en la formulación de esa transformación. Al producirse la restauración del Estado de Derecho y la revalorización profundamente cultural de los derechos humanos y su articulación con la vida, conflictos y disputas de los ciudadanos (presentes y ausentes) en las esferas privada y pública, estos componentes se han incorporado como un decisivo valor de cambio en la relación entre las series histórico-política y cultural-literaria del sistema. En esta dirección, la reescritura del Nunca Más en La ciudad ausente, por mencionar un caso emblemático, manifiesta y sugiere una multiplicidad de cuestiones (por ejemplo, que testimonio, declaración y ficción se articulan conformando otros tipos de mediaciones en este momento, realizando en ello modos singulares de compensación desde lo simbólico). Y en este sistema de relaciones, estimo, se asienta la conflictiva y fundamental apreciación de la memoria en la paradójica trama cultural e histórica, socioeconómica y política. Por esto, asimismo, seguimos escribiendo. Porque, como lee Saúl al final de Vivir afuera, "Escribir es pensar". Y es en este tránsito donde se disipan las nieblas.

BiBLIOGRAFÍA

Castoriadis, Cornelius. El avance de la insignificancia. Buenos Aires: Eudeba, 1997.

Chefjec, Sergio. Los planetas. Buenos Aires: Alfaguara, 1998.

Cohen, Marcelo. El testamento de O'Jaral. Buenos Aires: Alianza, 1995.

Hombres amables: dos incursiones de Georges LaMente. Barcelona: Norma, 1998.

Fogwill, Rodolfo. Mis muertos punk. Buenos Aires: Tierra Baldía, 1980.

Los pichy-cyegos: visiones de una batalla subterránea. Buenos Aires: De la Flor, 1983.

Pájaros de la cabeza. Buenos Aires: Catálogos, 1985.

Vivir afuera. Buenos Aires: Sudamericana, 1998. 
Gusmán, Luis, Villa. Buenos Aires: Alfaguara, 1996.

Jameson, Fredric. Policital Unconscious. Narrative as a Socially Symbolic Act. Ithaca, New York: Cornell University Press, 1981.

Morello-Frosch, Marta. “Las tretas de la memoria: Libertad Demitrópulos, Reina Roffé y Matilde Sánchez”. Memoria colectiva y políticas de olvido. Argentina y Uruguay, 1970-1990. Adriana Bergero y Fernando Reati, comps. Rosario: Beatriz Viterbo, 1997. 189-208.

Nunca Más. Informe de la Comisión Nacional sobre la Desaparición de Personas. Buenos Aires: Eudeba, 1984.

O’Donnell, Guillermo. Contrapuntos. Ensayos escogidos sobre autoritarismo y democratización. Buenos Aires/Barcelona/México: Paidós, 1997.

Perilli, Carmen. Las ratas en la Torre de Babel. La novela argentina entre 1982 y 1992. Buenos Aires: Ediciones Letra Buena, 1994.

Piglia, Ricardo. Respiración artificial. Buenos Aires: Pomaire, 1980. Prisión perpetua. Buenos Aires: Sudamericana, 1988.

La ciudad ausente. Buenos Aires: Sudamericana, 1992.

Cuentos morales: antología (1961-1990). Buenos Aires: Espasa-Calpe, 1994. Formas breves. Buenos Aires: Temas, 1999.

Crítica y ficción. [1986 y 1990]. Buenos Aires: Seix Barral, 2000.

Pons, María Cristina. Memorias del olvido. La novela histórica de fines del siglo XX. México: Siglo XXI, 1996.

Rivera, Andrés. La revolución es un sueño eterno. Buenos Aires: Grupo Editor Latinoamericano, 1987.

Rodríguez Pérsico, Adriana. “Introducción”. Ricardo Piglia. Cuentos morales. Buenos Aires: Austral, 1994.

Saer, Juan José. La pesquisa. Buenos Aires: Seix Barral, 1994.

Sánchez, Matilde. El Dock. Buenos Aires: Planeta, 1993.

Shumway, Nicolás. La invención de la Argentina. Historia de una idea. Buenos Aires: Emecé, 1993.

Vidal, Hernán. Cultura nacional chilena. Crítica literaria y derechos humanos. Minneapolis: Institute for the Study of Ideologies and Literature, 1989. 